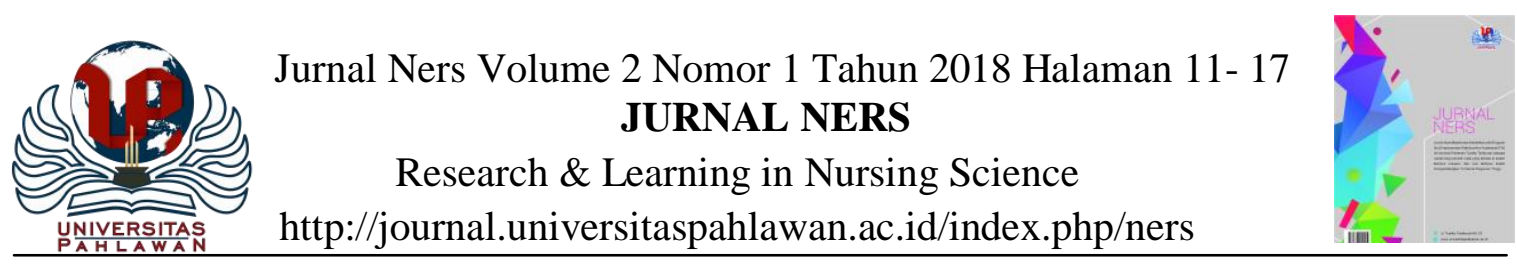

\title{
HUBUNGAN PERSONAL HYGIENE DENGAN KEJADIAN DERMATITIS KONTAK IRITAN PADA PEKERJA DI PT.PERINDUSTRIAN DAN PERDAGANGAN BANGKINANG TAHUN 2016
}

\author{
MILDA HASTUTY \\ Fakultas Ilmu Kesehatan, Universitas Pahlawan Tuanku Tambusai, Jl. Banda Aceh Gg. \\ Hidayat No.12A Kec. Bukit Raya Kota Pekanbaru \\ melda.obie@gmail.com
}

\begin{abstract}
Research surveillance in the United States states that $80 \%$ of occupational dermatitis is irritant contact dermatitis characterized by the presence of erythema (redness), edema (swelling) mild and cracked after the exposure of contents material from outside.Research to know the relationship of personal hygiene with incidence of disease skin (irritant contact dermatitis) to workers in PT. Industry and Trade Bangkinang in 2016. Cross Sectional research design, this research was conducted in Desember 2016 at PT. Industry and Trade Bangkinang. Sampel in this study are workers in PT. Industry and Trade Bangkinang numbering 92 people. Sample technique used Simple Random Sampling .. The data obtained were analyzed by chi square test. The results showed there was a personal hygiene relationship with irritant contact dermatitis on workers obtained $p$ value $=0,036$. For PT. Industry and Trade Bangkinang is expected to be a reference especially in designing rules, and policies for workers to prevent the occurrence of skin diseases (irritant contact dermatitis) by improving good personal hygiene and achieving a healthy work environment for its workers.
\end{abstract}

\section{Keywords: Personal Hygiene, Irritant Contact Dermatitis}

\begin{abstract}
Abstrak
Penelitian surveilans di Amerika menyebutkan bahwa $80 \%$ penyakit kulit akibat kerja adalah dermatitis kontak iritan ditandai dengan adanya eritema (kemerahan), edema (bengkak) ringan dan pecah-pecah setelah terjadi pajanan bahan kontaktan dari luar.Tujuan penelitian untuk mengetahui hubungan personal hygienedengan kejadian penyakit kulit (dermatitis kontak iritan) pada pekerja di PT. Perindustrian dan Perdagangan Bangkinang tahun 2016. Desain penelitian Cross Sectional, penelitian ini dilaksanakan pada Desember 2016 di PT. Perindustrian dan Perdagangan Bangkinang.Sampel dalam penelitian ini adalah pekerja di PT. Perindustrian dan Perdagangan Bangkinang yang berjumlah 92 orang. Teknik sampel yang digunakan Simple Random Sampling..Data yang diperoleh dianalisis dengan uji chi square. Hasil penelitian menunjukkan ada hubungan personal hygiene dengan dermatitis kontak iritan pada pekerja diperoleh $p$ value $=0,036$. Bagi PT. Perindustrian dan Perdagangan Bangkinang diharapkan dapat menjadi referensi terutama dalam merancang aturan, dan kebijakan bagi pekerja untuk mencegah terjadinya kejadian penyakit kulit (dermatitis kontak iritan) dengan meningkatkan personal hygiene yang baik dan tercapainya lingkungan kerja yang sehat bagi para pekerjanya.
\end{abstract}

Kata Kunci $\quad$ : Personal Hygiene, Dermatitis Kontak Iritan 


\section{PENDAHULUAN}

Tempat kerja dikenal sebagai lingkungan yang megandung berbagai sumber bahaya dan mengancam keselamatan dan kesehatan pekerja. Dari kenyataan tersebut maka ditetapkanlah syarat-syarat keselamatan kerja pada Undang-undang No. 1 Tahun 1970 Tentang Keselamatan Kerja yang salah satu isinya mengamanahkan agar dilakukannya pencegahan dan pengendalian suhu, kelembaban, debu, kotoran, asap, uap, gas, hembusan angin, cuaca, sinar atau radiasi, suara, dan getaran. Lebih jauh lagi, UU ini mengamanahkan dilakukannya pencegahan dan pengendalian Penyakit Akibat Kerja (PAK) (Depnakertrans, 2007).

Penyakit-penyakit akibat kerja telah lama dikenal dan diketahui, termasuk penyakit kulit akibat kerja yang lebih dikenal dengan occupational dermatitis.Penyakit kulit akibat kerja merupakan sebagian besar dari penyakit akibat kerja pada umumnya dan diperkirakan 50-75\% dari seluruh penyakit akibat kerja (Saftarina, 2014).

Menurut data International Labour Organization (ILO) tahun 2013, 1 pekerja di dunia meninggal setiap detik karena kecelakaan kerja dan 160 pekerja mengalami penyakit akibat kerja.Penelitian surveilans di Amerika menyebutkan bahwa $80 \%$ penyakit kulit akibat kerja adalah dermatitis kontak.Di antara dermatitis kontak, dermatitis iritan menduduki urutan kedua dengan 14\%-20\% (Sarfiah, 2016).

Dermatitis adalah peradangan kulit (epidermis dan dermis) sebagai respon terhadap pengaruh faktor eksogen dan atau faktor endogen, menyebabkan kelainan klinis berupa efloresensi polimorfik dan keluhan gatal.Tanda polimorfik tidak selalu terjadi bersamaan, bahkan mungkin hanya satu jenis misalnya berupa papula (oligomorfik). Dermatitis cendrung residif dan menjadi kronis (Menaldi, 2016).

Dermatitis kontak adalah suatu peradangan kulit yang disertai adanya spongiosis/edema interseluler karena kulit berinteraksi dengan bahan-bahan kimia yang berkontak atau terpajan pada kulit (Harahap M, 2009).

Dermatitis kontak iritan merupakan reaksi inflamasi lokal pada kulit yang bersifat non imunologik, ditandai dengan adanya eritema (kemerahan), edema (bengkak) ringan dan pecah-pecah setelah terjadi pajanan bahan kontaktan dari luar.Bahan kontakan ini dapat berupa bahan fisika atau kimia yang dapat menimbulkan reaksi pada kulit (Febria Syuryani 2011).

Dampak dermatitis kontak iritan dapat mengurangi produktifitas pekerja karena gejalanya dapat mengganggu pekerjaan. Di Amerika Serikat biaya yang digunankan untuk menanggulangi kelainan kulit kulit akibat kerja cukup besar, yang mencakup kehilangan penghasilan, produktifitas, dan pemindahan tenaga kerja, ganti rugi, biaya pengobatan, dan asuransi (Djunaedi, 2007)

Faktor yang juga berperan dalam penularan penyakit kulit (dermatitis kontak iritan) adalah sosial ekonomi yang rendah, higiene perseorangan yang jelek, lingkungan yang tidak saniter dan perilaku yang tidak mendukung kesehatan. Faktor yang paling dominan adalah kemiskinan dan perilaku higiene perseorangan yang jelek (ma'rufi, 2005).

Personal hygiene adalah kebersihan dan kesehatan perorangan yang bertujuan untuk mencegah timbulnya penyakit pada diri sendiri 
maupun orang lain (Tarwotodan Wartonah, 2009).

Terjadinya penyakit yang berhubungan dengan pekerjaan dan PAK sering terjadi pada pekerja. Penelitian World Health Organization (WHO) pada pekerja tentang PAK di 5 (lima) benua tahun 2007, memperlihatkan bahwa penyakit gangguan otot rangka (Musculoskeletal Disease) pada urutan pertama $48 \%$, kemudian gangguan jiwa 10-30 \%, penyakit paru obstruksi $11 \%$, penyakit kulit (Dermatitis) akibat kerja 10\%, gangguan pendengaran 9\%, keracunan pestisida 3\%, cedera dan lain-lain. Berdasarkan data tersebut, penyakit kulit akibat kerja menempati urutan keempat dalam PAK (Lestari, 2007)

Prevalensi dermatitis di Indonesia sangat bervariasi. Pada pertemuan Dokter spesialis kulit tahun 2009 dinyatakan sekitar $90 \%$ penyakit kulit akibat kerja merupakan dermatitis kontak, baik iritan maupun alergik. Penyakit kulit akibat kerja merupakan dermatitis kontak sebesar 92,5\%, diantaranya sekitar 5,4\% karena infeksi kulit dan 2,1\% penyakit kulit karena sebab lain (Rofi Y, 2016)

Menurut profil Dinas Kesehatan Provinsi Riau kota Pekanbaru tahun 2014 menunjukkan 10 penyakit terbesar yaitu, ISPA 70.983 kasus, Hipertensi20.601 kasus, Artritis Rheumatoid 12.882 kasus, Gastritis dan Duodenitis 12.642 kasus, Infeksi Kulit dan Jar Subkutan 12.424 kasus, Penyakit Pulpa dan Peripikal 11.975 kasus, Dispepsia 11.716 kasus, Influenza 10.965 kasus, Dermatitis Akibat Kerja 9.439 kasus, dan Penyakit Kulit Jaringan Subkutan 9.092 kasus.

Sedangkan kasus gangguan penyakit kulit (Dermatitis) di Kabupaten Kampar dapat dilihat pada tabel berikut:

\section{Tabel 1.1 Kasus Kejadian Penyakit Kulit (Dermatitis kontak iritan)diKabupaten KamparTahun 2014-2015}

\begin{tabular}{ccc}
\hline No & $\begin{array}{c}\text { Kejadian Penyakit Kulit } \\
\text { (Dermatitis) }\end{array}$ & Kasus \\
\hline 1 & 2014 & 129 \\
\hline 2 & 2015 & 237
\end{tabular}

Berdasarkan tabel diatas diketahui bahwa kasus kejadian penyakit kulit (dermatitis) banyak terjadi ditahun 2015 sebanyak 237 kasus.

Sedangkan kasus gangguan penyakit kulit (Dermatitis) di PT. Perindustrian dan Perdagangan Bangkinang dapat dilihat pada tabel berikut:

Tabel 1.2 Kasus Kejadian Penyakit Kulit (Dermatitis kontak iritan) di PT. Perindustrian dan Perdagangan Bangkinang Tahun 20142015

\begin{tabular}{ccc}
\hline No & $\begin{array}{c}\text { Kejadian Penyakit Kulit } \\
\text { (Dermatitis) }\end{array}$ & Kasus \\
\hline 1 & 2014 & 27 \\
\hline 2 & 2016 & 30 \\
\hline
\end{tabular}

Berdasarkan tabel diatas diketahui bahwa kasus kejadian penyakit kulit (dermatitis) banyak terjadi ditahun 2015 sebanyak 30 kasus.

PT. Perindustrian \&Perdagangan Bangkinang adalah salah satu perusahaan karet yang berlokasi Jalan Prof M Yamin, SH, Kelurahan Langgini, Kecamatan Bangkinang, Kabupaten Kampar yang dimana Blanket crepe sebagai hasil produksinya. PT. Perindustrian danPerdagangan mempunyai lahan seluas $8.071 \mathrm{~m}^{2}$ dan kapasitas olah pabrik 9.000 ton / tahun.

Berdasarkan survei awal pada tanggal Agustus 2016 yang dilakukan di PT. Perindustrian dan Perdagangan 
Bangkinang ditemui $40 \%$ dari 62 orang pernah mengalami penyakit kulit (dermatitis kontak iritan) dan hampir setiap tahun pekerja terkena penyakit kulit (dermatitis kontak iritan).

Dari hasil observasi peneliti juga melihat bahwa pekerja tidak melakukan personal hygiene dengan baik. Dari 25 orang pekerja yang diwawancarai mereka mengatakan seluruhnya tidak menggunakan APD yang lengkap karena APD yang kurang maka pekerja harus menggunakan secara bergantian pada sip kerja yang sama, 10 pekerja tidak mencuci tangan dengan sabun setelah bekerja, 15 pekerja tidak memakai pakaian kerja menutupi seluruh kulit tubuh.

Penggunaan APD sarung tangan secara benar sangat efektif untuk mencegah penyakit kulit akibat kerja. Jenis sarung tangan yang digunakan sebaiknya disesuaikan jenis iritan yang ditangani dan jenis proses kerja yang di lakukan. Sarung tangan harus menutupi sepertiga lengan bawah agar efektif penggunaannya (Ningtiyas, 2013).

Berdasarkan latar belakang tersebut maka penulis tertarik untuk mengetahui lebih jauh dan secara langsung mengenai hubungan personal higiene dengan penyakit kulit (dermatitis kontak iritan) pada pekerja pekerja PT. Perindustrian dan Perdagangan Bangkinang Tahun 2016.

Tujuan penelitian ini adalah untuk mengetahui hubungan personal higiene dengan penyakit kulit (dermatitis kontak iritan) pada pekerja pekerja PT.Perindustrian dan Perdagangan Bangkinang Tahun 2016.

\section{METODE}

Penelitian ini menggunakan desain penelitian analitik dengan rancangan Crossectional, karena pengukuran variabel bebas (personal higiene) dengan variabel terikat (penyakit kulit (dermatitis kontak iritan)) dilakukan sekali waktu pada saat yang bersamaan (Notoatmodjo, 2007).

Penelitian ini dilakukan di PT. Perindustrian dan Perdagangan Bangkinang Tahun 2016 yang dilaksanakan pada bulan Desember 2016. Populasi dalam penelitian ini adalah seluruh tenaga kerja PT. Perindustrian dan Perdagangan Bangkinang, yang berjumlah 119 orang tenaga kerja yang berada di area PT yang akan diteliti. Sampel nya adalahtenaga pengolahan karet bagian produksi yang aktif bekerjayang berjumlah 92 orang.

Teknik pengambilan sampel menggunakan teknik Simple Random Sampling yaitu setiap anggota atau unit dari populasi mempunyai kesempatan yang sama untuk di seleksi sebagai sampel (Notoadmojo,2012).

Alat pengumpulan data yang yang dilakukan dalam penelitian ini adalah lembar pertanyaan kuesioner yang digunakan untuk memperoleh data yang dibutuhkan. Lembar kuesioner yaitu suatu daftar pertanyaan yang berisi nama subjek dan beberapa pertanyaan lainnya dari sasaran pengamatan (Noatoatmodjo, 2010). Alat pengumpulan data pada penelitian ini dilakukan dengan menggunkan data primer dan sekunder.

Analisis univariat dilakukan untuk mendeskripsikan karakteristik masingmasing variabel penelitian dalam bentuk tabel distribusi frekuensi. Analisis univariat akan mendeskripsikan dalam bentuk tabel distribusi frekuensi untuk variabel independen yaitu: personal hygiene, sedangkan variabel dependen yaitu: penyakit kulit (Dermatitis kontak iritan) di PT. Perindustrian dan Perdagangan.

Analisis bivariat dilakukan untuk mengetahui hubungan antara beberapa variabel independen dengan variabel 
dependen. Tujuannya untuk menguji ada tidaknya hubungan personal hygiene, dengan penyakit kulit (dermatitis kontak iritan) dengan uji statistik Chi-square. Dasar pengambilan uji chi square dengan tingkat kemaknaan $95 \%$ dengan kriteria :

1. Jika nilai $\mathrm{p}$-value $<\alpha(0,05)$ maka Ho ditolak artinya menunjukkan variabel tersebut ada hubungan.

2. Jika nilai $p$-value $\geq \alpha(0,05)$ maka Ha diterima artinya menunjukkan variabel tersebut tidak ada hubungan.

Hasil pengamatan kemudian diidentifikasi faktor risiko yang disusun dengan menggunakan tabel $2 \times 2$, biasanya yang dihitung adalah Prevalens Odds Ratio, yaitu dengan membagi prevalensi efek pada kelompok dengan faktor risiko dengan prevalensi efek pada kelompok tanpa faktor risiko.

HASIL

\section{A. Analisis Univariat}

Dalam penelitian ini akan dibahas mengenai deskripsi data dari variabel penelitian dan pengaruh variabel yaitu Personal hygienedengan variabel terikat Kejadian Penyakit Kulit (Dermatitis kontak iritan) Pada Pekerja PT.Perindustrian dan Perdagangan Bangkinang Tahun 2016.

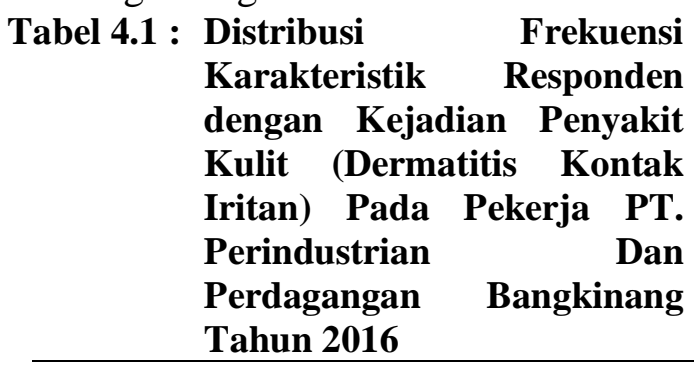

\begin{tabular}{clcc}
\hline No & Karakteristik & $\begin{array}{c}\text { Frekuensi } \\
\text { (n) }\end{array}$ & $\begin{array}{c}\text { Persentase } \\
(\mathbf{\%})\end{array}$ \\
\hline & $\begin{array}{l}\text { Dermatitis } \\
\text { kontak iritan }\end{array}$ & & \\
\hline & $\begin{array}{l}\text { Dermatitis } \\
\text { kontak iritan }\end{array}$ & 59 & 64,1 \\
\hline
\end{tabular}

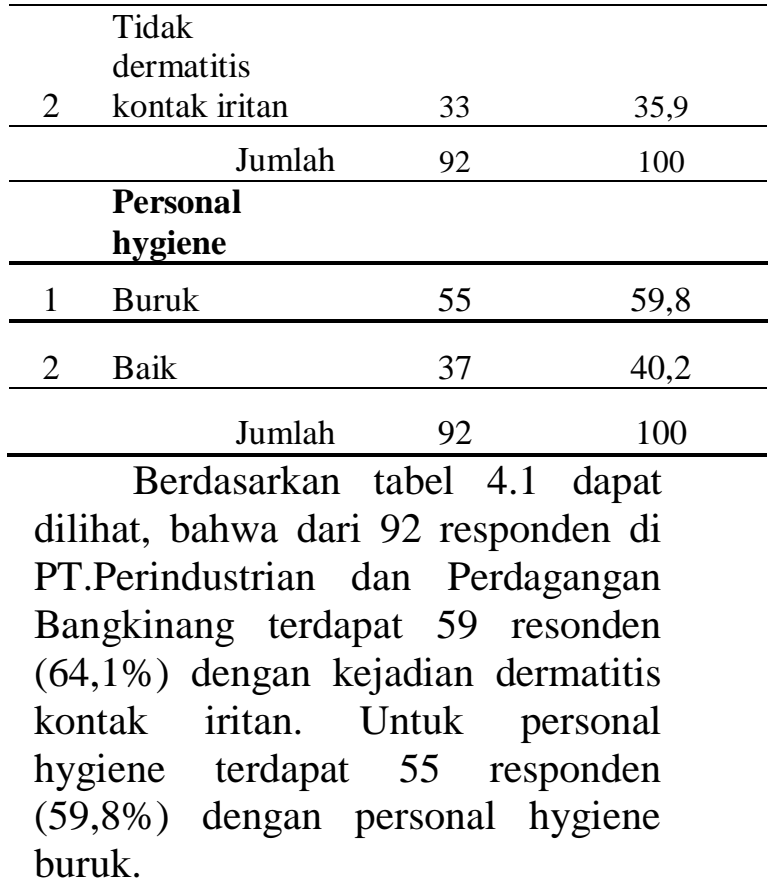

\section{B. Analisis Bivariat}

Analisis bivariat dilakukan untuk melihat hubungan suatu variabel independen dengan satu variabel depanden.

\section{Tabel4.2 : Hubungan Personal} Hygiene dengan Kejadian Penyakit Kulit (Dermatitis Kontak Iritan) pada Pekerja di PT. Perindustrian dan Perdagangan Bangkinang Tahun 2016

\section{Kejadian penyakit kulit}

(dermatitis kontak iritan)

\begin{tabular}{ccccccccc} 
Personal & \multicolumn{9}{c}{ hygiene } & $\begin{array}{c}\text { Dermatitis } \\
\text { kontak } \\
\text { iritan }\end{array}$ & $\begin{array}{c}\text { Tidak } \\
\text { dermatitis } \\
\text { kontak } \\
\text { iritan }\end{array}$ & Total & $\begin{array}{c}\text { p - } \\
\text { value }\end{array}$ & $\begin{array}{c}\text { POR } \\
\text { (CI; } \\
\mathbf{9 5 \% )}\end{array}$ \\
\hline \multicolumn{1}{c}{$\mathrm{N}$} & $\%$ & $\mathrm{~N}$ & $\mathbf{\%}$ & $\mathrm{N}$ & $\%$ & & 2,526 \\
\hline Buruk & 40 & 72,7 & 15 & 27,3 & 55 & 100 & 0.036 & $(1,052-$ \\
\hline Baik & 19 & 51,4 & 18 & 48,6 & 37 & 100 & & $6,068)$ \\
\hline Total & 59 & 64,1 & 33 & 35,9 & 92 & 100 & \\
\hline \multicolumn{6}{l}{ Berdasarkan tabel 4.2 diketahui }
\end{tabular}
bahwa dari 55 responden dengan personal hygiene buruk, yang tidak terjadi dermatitis kontak iritan sebanyak 15 responden (27,3\%). Sedangkan dari 37 responden dengan personal hygiene yang baik, terjadi 
dermatitis kontak iritan sebanyak 19 reponden $(51,4 \%)$. Berdasarkan hasil uji statistik Chi Square diperoleh nilai $\mathrm{p}$ value $=0,036 \leq 0,05$ yang artinya ada hubungan antara personal hygienepekerja dengan kejadian dermatitis pada pekerja.

\section{PEMBAHASAN}

Berdasarkan hasil penelitian yang dilakukan di PT. Perindustrian dan Perdangan Bangkinang Tahun 2016, diperoleh hasil dari 92 pekerja terdapat $55(59,8 \%)$ pekerja dengan personal hygiene buruk dan 37 (40,2\%) pekerja dengan personal hygiene baik. Dari hasil uji statistic Chi Square, diperoleh $p$ value 0,036 karena $\mathrm{p}$ value $\leq 0,05$ maka Ho ditolak, artinya ada hubungan yang bermakna antara variabel Personal hygiene dengan Kejadian Dermatitis kontak iritan di PT. Perindustrian dan Perdagangan Bangkinang Tahun 2016. Nilai Prevalence Odd Ratio $(\mathrm{POR})=$ 2,526 menunjukkan bahwa pekerja dengan personal hygiene buruk berisiko 3 kali lebih besar menderita penyakit dermatitis kontak iritan daripada pekerjadengan personal hygiene baik.

Menurut asumsi peneliti, dari 55 responden dengan personal hygiene buruk di dapat 15 responden tetapi tidak terkena dermatitis kontak iritan hal ini dikarenakan responden memiliki imunitas tubuh yang tinggi sehingga walaupun terpapar dengan bahan kimia tetap tidak terkena dermatitis kontak iritan, dan dari 37 responden yang memiliki personal hygiene yang baik didapat 19 responden terkena dermatitis kontak iritan hal ini dikarenakan responden memiliki imunitas tubuh yang rendah sehingga walaupun terpapar sedikit saja bahan kimia tetap terkena dermatitis kontak iritan dan juga fasilitas kebersihan ditempat kerja tidak memadai untuk digunakan responden.

Hasil penelitian ini sejalan dengan penelitian yang dilakukan oleh Dinar Witasari (2014) yang menyatakan bahwa terdapat hubungan yang bermakna antara personal hygiene dengan kejadian dermatitis kontak iritan pada pekerja. Dimana yang menyatakan bahwa terdapat hubungan yang bermakna antara personal hygiene dengan kejadian Dermatitis kontak iritan pada pekerja. Dimana dari 39pekerjadengan personal hygiene buruk terdapat 30 responden (77\%) yang mengalami dermatitis kontak iritan dan 9 responden (23\%) tidak mengalami dermatitis kontak iritan. Sedangkan dari 22 responden yang memiliki personal higiene baik terdapat 3 responden (14\%) yang mengalami dermatitis kontak iritan dan 19 responden $(86 \%)$ tidak mengalami dermatitis kontak iritan. Hasil uji statistik didapatkan $\mathrm{p}$ Value $=0,000$ $(\mathrm{p}<0,05)$.

Kebersihan Perorangan (personal hygiene) adalah konsep dasar dari pembersihan, kerapihan dan perawatan badan kita.Sangatlah penting untuk pekerja menjadi sehat dan selamat ditempat kerja.Kebersihan perorangan pekerja dapat mencegah penyebaran kuman dan penyakit, mengurangi paparan pada bahan kimia dan kontaminasi, dan melakukan pencegahan alergi kulit, kondisi kulit dan sensitifitas terhadap bahan kimia (Chohen, 2007).

\section{SIMPULAN}

Berdasarkan hasil penelitian yang dilakukan pada bulan Juni 2016 di PT. Perindustrian dan Perdagangan Bangkinang dengan melihat hubungan personal higiene dengankejadian penyakit kulit (dermatitis kontak iritan) pada pekerja di PT. Perindustrian dan 
Perdagangan Bangkinang tahun 2016 dapat disimpulkan:

1. Diketahui dari 92 responden terdapat $59(64,1 \%)$ dengan kejadian dermatitis kontak iritan, dan 55 $(59,8)$ responden dengan personal hygiene buruk

DAFTAR PUSTAKA

Departemen Tenaga Kerja dan Transmigrasi (2007). Himpunan Peraturan Perundang-undangan Keselamatan dan Kesehatan Kerja.

Dinas Kesehatan Kabupaten Kampar (2014), Jumlah Penyakit Kulit (Dermatitis) Akibat Kerja di Dinas Kesehatan Kabupaten Kampar.

(2015), Jumlah Penyakit Kulit (Dermatitis) Akibat Kerja di Dinas Kesehatan Kabupaten Kampar.

(2016), Jumlah Penyakit Kulit (Dermatitis) Akibat Kerja di
2. Terdapat hubunganantara personal hygienedengan dermatitis kontak iritan pada pekerja PT. Perindustrian dan Perdagangan Bangkinang Tahun 2016

Dinas Kesehatan Kabupaten Kampar.

Hidayat, A. (2010), Metode Penelitian Kebidanan dan Teknik Analisis Data, Jakarta : Salemba Medika.

Lapau, B. (2015), Metode Penelitian Kesehatan, Jakarta : Yayasan Pustaka Obor Indonesia

Menaldi. (2016), Ilmu Penyakit Kulit Dan Kelamin Edisi Ketujuh, Jakarta : Badan Penerbit FKUI.

Profil Kesehatan Provinsi Riau (2014)

Soedarto, (2014), Alergi dan Penyakit Sistem Imun, Jakarta : Penerbit Buku Sagung Seto. 